NANOSCIENCE AND TECHNOLOGY- AN INTERNATIONAL JOURNAL

ACCEPTED NOVEMBER $13^{T H} 2019$

\title{
COMPUTATION OF GOLD-WATER NANOFLUID NATURAL CONVECTION IN A THREE-DIMENSIONAL TILTED PRISMATIC SOLAR ENCLOSURE WITH ASPECT RATIO AND VOLUME FRACTION EFFECTS
}

\author{
Sireetorn Kuharat ${ }^{1}$, O. Anwar Bég ${ }^{1 *}$, Ali Kadir ${ }^{1}$, B. Vasu ${ }^{2 *}$, Tasveer A. Bég ${ }^{3}$ and W. S. Jouri ${ }^{1}$ \\ ${ }^{1}$ Aeronautical \& Mechanical Engineering Department, School of Science, Engineering and \\ Environment, Newton Building, University of Salford, Manchester, M54WT, UK. \\ ${ }^{2}$ Department of Mathematics, Motilal Nehru National Institute of Technology Allahabad, Prayagraj, \\ Uttar Pradesh- 211004, India \\ ${ }^{3}$ Renewable Energy/Computational Mechanics, Israfil House, Dickenson Rd., Manchester, M13, UK. \\ Emails-S.Kuharat@edu.salford.ac.uk; O.A.Beg@salford.ac.uk; A.Kadir@salford.ac.uk; \\ tasveerabeg@gmail.com; w.s.jouri@salford.ac.uk
}

*Corresponding author - email: bvasu@mnnit.ac.in

\begin{abstract}
Nanofluids are increasingly being deployed in numerous energy applications owing to their impressive thermal enhancement properties. Motivated by these developments in the current study we present finite volume numerical simulations of natural convection in an inclined 3-dimensional prismatic direct absorber solar collector (DASC) containing gold-water nanofluid. Steady-state, incompressible laminar Newtonian viscous flow is assumed. The enclosure has two adiabatic walls, one hot (solar receiving) and one colder wall. ANSYS FLUENT software (version 19.1) is employed. The Tiwari-Das volume fraction nanofluid model is utilized to simulate nanoscale effects and allows a systematic exploration of volume fraction effects. The effects of thermal buoyancy (Rayleigh number), geometrical aspect ratio and enclosure tilt angle on isotherm and temperature contour distributions are presented with extensive visualization in three dimensions. Grid-independence tests are included. Validation with published studies from the literature is also conducted. A significant modification in vortex structure and temperature distribution is computed with volume fraction, Rayleigh number, aspect ratio and tilt angle. Heat flux and average Nusselt number results are also included. Gold nano-particles even at relatively low volume fractions are observed to achieve substantial improvement in heat transfer characteristics.
\end{abstract}

KEY WORDS: Gold nano-particles; prismatic direct absorber solar collector; inclination; dilute aqueous nanofluid; finite volume method; thermal buoyancy; isotherms; streamlines; aspect ratio; volume fraction; thermal conductivity; Nusselt number.

\section{INTRODUCTION}

Natural convection in three-dimensional enclosures is a fundamental area of thermal engineering sciences of relevance to geophysics, materials processing, food process technology and energy systems. It has been studied extensively both from a theoretical and computational perspective and also experimentally with a focus on visualization. Many studies including Hiller et al. [1] have identified the complex spiral vortex structures generated in threedimensional flows under buoyancy effects. While experimental studies have been important, 
since the advent of more powerful computer resources and commercial field solvers, numerical simulation has increasingly become a major area of activity since it provides a relatively inexpensive and less time-consuming methodology for predicting such flows. Numerical simulation also provides a good compliment to experimental investigations since the data from the latter can be used as important benchmark cases for validation of computational codes. Many different computational methodologies are available now in this regard including molecular dynamics, Lattice Boltzmann methods, finite element techniques and finite difference or finite volume solvers [2]. Mallinson and de Vahl Davis [3] were among the first researchers to investigate 3 -dimensional natural convection in a box-like enclosure. They employed a finite element method and identified that at intermediate Rayleigh numbers a strong convective motion is mobilized due to the inertial interaction of the rotating flow with the stationary walls together with a contribution arising from buoyancy forces generated by longitudinal temperature gradients. They also showed that with stronger thermal buoyancy (higher Rayleigh numbers), there is an emergence of multiple longitudinal flows develop which are controlled by aspect ratios, Prandtl number and Rayleigh number. Fugesi et al. [4] used a three-dimensional finite-difference method to analyze natural convection flows of air flow in a differentially heated cubical box with isothermal vertical sidewalls at different temperatures and the remaining vertical walls (end walls) being thermally insulated. They considered both adiabatic and perfectly conducting wall boundary conditions and observed enhanced heat transfer in the latter case. Natural convection in three dimensional enclosures is also a major area of interest in solar engineering, in particular in the design of direct absorber solar collectors (DASCs). Sharma et al. [5] employed the PHOENICS solver to investigate the threedimensional thermosyphon flow in an unglazed solar flat plate collector and computed mass flow rates in the collector loop for a range of solar heat flux inputs. Li et al. [6] applied a multiple-relaxation-time model (MRT) and lattice Boltzmann method (LBM) solver to analyze the three-dimensional cubic natural convection for a solar cell at various Rayleigh numbers. They considered a variety of thermal boundary conditions including adiabatic and linear temperature variations.

A significant development in $21^{\text {st }}$ century engineering has been the emergence of nanomaterials. Engineers are increasingly designing systems at the nanoscale and important progress has been made in nanotube-embedded gels, nano-lubricants, electro-conductive nanopolymers etc. An important sub-group of liquid nanomaterials is nanofluids. Introduced in the 1990s, these complex fluids were developed primarily to achieve substantial improvements in 
thermal enhancement. They are synthesized by doping conventional working fluids e.g. water, polymers, ethylene glycol etc, with either metallic or carbon-based nanoparticles with average particle sizes below $100 \mathrm{~nm}$. The resulting colloidal suspension achieves superior thermal conductivity, heat capacity and viscosity properties compared with macroscopic fluids. An impressive range of industrial sectors have embraced nanofluid technology including nuclear reactor cooling, marine lubricants, polymer coating processes, combustion and power. Solar power design has also benefited considerably from the utilization of nanofluids in multiple configurations. Campos et al. [7] conducted photothermal conversion experiments on waterbased nanofluids doped with spherical gold, silver, and copper nanoparticles, non-spherical silver nanoparticles, layered graphene oxides and hybrid graphene oxide/silver hybrid structures, for direct absorption solar collectors under 1000 Watts of solar radiation flux. They observed that gold and copper nanofluids achieved the best thermal efficiencies. Mallah et al. [8] investigated the deployment of silver plasmonic nanofluids (which feature localized surface plasmon resonance phenomenon to enhance the extinction efficiency of the plasmonic nanoparticle several times at the resonance wavelength) in direct absorber solar collectors. They showed that silver nanoparticles exhibit a high intensity of the localized surface plasmon, which which may be precisely adjusted via shape, size and aspect ratio of nano-particles to perform within the broadband $350-1200 \mathrm{~nm}$. They further showed via computational simulation that nanofluids composed of blended Ag nano-morphologies achieve a significant improvement in absorbance over the entire solar spectrum and elevate efficiency of the direct solar collector to in excess of $85 \%$ even at low volume fractions. Further investigations of nanofluid-based solar collectors have been communicated by Farhana et al. [9] (who have reviewed multiple metallic hybrid types), Jin et al. [10] (who have identified exceptional photothermal conversion efficiencies of gold and silver nano-particles), Gimeno-Furio et al. [11] (who have explored oil-based carbon "black" nanofluids in various solar receiver geometries including prisms, annular and parabolic troughs), Shah et al. [12] (copper oxide nanofluids), Dehaj et al. [13] (magnesium oxide nanofluids for heat pipe solar systems) and Bellos et al. [14] (alumina and titania-water nanofluids for solar concentrators). Khanafer and Vafai [15] presented a succinct review of many aspects of solar nanofluid technology including solar stills, photovoltaic/thermal systems, doping methods, cost-benefit analysis and sustainability. Zayed et al. [16] addressed flat plate solar collector nanofluid performance considering a variety of metal, metal oxides, semiconductor crystalized oxides, and carbon based nanofluids as the absorbing media and noting that copper oxide achieves the best efficiency whereas carbon based nanofluids achieved both superior energy and exergy efficiencies. Mehmood et al. [17] investigated the manufacturing flows of solar copper oxide- 
doped nano-polymer coatings for photo-voltaic applications, noting their superiority in durability, anti-corrosion and thermal efficiency. Dugaria et al. [18] studied computationally the thermal performance of aqueous nanofluids containing suspensions of single wall carbon nano-horns (SWCNHs) as volumetric absorbing media in a concentrating direct absorption parabolic trough solar collector. They presented extensive solutions of the coupled energy balance and radiative heat transfer equations for a participating medium, and elaborated in detail the variation in heat transfer rates, thermal absorption and penetration distance of the concentrated solar radiation inside the nanofluid volume. Other interesting studies of nanofluid solar absorbers have been communicated by Zhang et al. [19[ (for solar-powered distillation systems), Zeiny et al. [20] (for large scale solar evaporation projects), Bait et al. [21] (for combined thermal and mass diffusion in metallic nanofluid solar still designs) and Mehrali et al. [22] (for graphene/silver plasmonic nanofluid solar thermal conversion).

The above studies have generally confirmed the excellent advantages of utilizing nanofluids in solar energy technology. As noted earlier, computational models provide a very important parallel methodology to experimental and field testing to optimize solar thermal energy harvesting. Since the differential equation systems describing heat transfer and fluid dynamics in nanofluid collectors are generally nonlinear, many numerical approaches have been explored to solve these boundary value problems. These techniques include symbolic software such as MAPLE [23], homotopy analysis method [24], computational fluid dynamics (CFD) software [25], finite difference algorithms [26] and decomposition methods [27]. These approaches have allowed a deeper insight into the numerous microscopic and macroscopic factors which contribute to solar nanofluid performance. For three-dimensional analysis, CFD remains the most powerful approach available to solar engineers. Tafarroj et al. [28] used a finite volume code (CFD-ACE) to study the influence of nanosilica and multi-wall carbon nanotube (MWCNT) doped ethylene glycol (EG) nanofluids in a solar direct absorption parabolic trough collector (DAPTC) for an extensive range of volume fractions. They also included a multilayer perceptron neural network to optimize data from the CFD model achieving good correlation with experiments. Kuharat and Bég [29] recently deployed ANSYS FLUENT finite volume software to compute the performance of titanium oxide, silver and copper -water nanofluids in a two-dimensional rectangular direct absorber solar collector, noting that silver achieves excellent performance over the widest range of volume fractions although copper achieves the overall highest thermal efficiency. Fattahi et al. [30] employed a DQ9 grid in Lattice Boltzmann computations of natural convection in a square solar enclosure containing alumina and copper -water nanofluids for Rayleigh numbers ranging from 1000 to 1000,000 and volume fractions up to 5\%, noting that copper achieves higher heat transfer rates (Nusselt 
numbers). Balakin et al. [31] used the commercial CFD package, STAR-CCM+, to simulate the multiphase thermo-magnetic convection in ionic carbon nano-particle doped nanofluids in a direct absorption collector, observing that magnetic nanofluids attain $30 \%$ enhancement in collector efficiency. Selmi et al. [32] investigated solar irradiation and mixed convection and radiation heat transfer in a flat plate solar energy collector with and without circulating water flow using a finite element CFD approach. Rose et al. [33] use the COMSOL finite element code to study the absorption of graphene oxide nanoparticles suspended in ethylene glycol base fluid for solar radiation (380-800 nm), noting that an optimum volume fraction of $0.012 \%$ of graphene oxide is obtained achieving a minimum reflectance and highest absorbance over the visible spectral range. Nasiri et al. [34] presented a weakly compressible smoothed particle hydrodynamics (WC-SPH) numerical simulation of nano-fluid forced convection heat transfer for a cylindrical solar collector geometry for Prandtl numbers of 0.01 to 40 and metallic nanoparticle volumetric concentrations ranging from 0 to $4 \%$. Nasrin et al. [35] used a penalty finite element software to simulate the impact of Prandtl number on natural convection flow in a $\mathrm{Al}_{2} \mathrm{O}_{3}$-water nanofluid solar collector enclosure with a glass cover plate and sinusoidal absorber is done.

The above studies did not consider the tilt of the solar collector enclosure. To optimize the capture of solar energy by collectors, they are frequently orientated at a specific angle i.e. tilted upwards. To produce more realistic predictions of heat transfer rates, mathematical models need to incorporate inclination of the direct absorber collector. Several researchers have explored the influence of inclination on thermo-fluid characteristics in solar absorbers. Esfandiary et al. [36] used the two-phase mixture Buongiorno nanoscale model and a finite volume method to analyse the influence of inclination angle on natural convective heat transfer and fluid flow in an enclosure filled with $\mathrm{Al}_{2} \mathrm{O}_{3}$-water nanofluid. They noted that maximum Nusselt number is attained with a 30 degrees tilt angle. Motlagh et al. [37] studied computationally the natural convection of alumina-water nanofluid inside a tilted square enclosure with non-homogenous two-phase Buongiorno's model and the Patankar SIMPLE algorithm. They showed that at any title angle and at low Rayleigh numbers, the particle distribution is non-uniform whereas a more homogenous distribution is achieved at high Rayleigh numbers (strong thermal buoyancy). Gachem et al. [38] used a vorticity-vector potential formulation to simulate the combined natural convection and radiation in an inclined solar thermal collector containing a gray medium.

In the present article, finite volume computational fluid dynamics simulations of steady-state nanofluid natural convection in a three-dimensional enclosure containing gold-water nanofluid 
are described. Incompressible, laminar, Newtonian viscous flow is considered with natural convection. The ANSYS FLUENT finite volume code (version 19.1) [29] is employed. The Tiwari-Das volume fraction nanofluid model is used and spherical, homogenously distributed gold nano-particles are considered. Metal nanoparticles can contribute to effective light absorption in solar collectors via both local-field enhancement through localized surface plasmon resonance and by light scattering leading to prolonged optical path lengths. Gold is one of the most popular nanoparticles therefore since it achieves excellent surface plasmon resonance can be tuned in the visible wavelength region [39]. However, to the authors' knowledge, thus far 3-dimensional computational simulations of gold-water nanofluid solar direct absorbers have not been reported in the literature. The superior optical and thermophysical properties of gold nano-particles (relative to other metallic nanomaterials) have been shown to achieve superior thermal conductivity, suspension stability and long term performance in the field which are all key factors required to enhance solar energy absorption and conversion [39]. In this regard, the deployment of gold nano-particles in 3-D numerical simulations in a tilted prismatic enclosure constitutes a new direction in solar absorber research and the novelty of the present work. Extensive visualizations of streamline and isotherm distributions for a range of gold nanoparticle volume fraction, geometrical aspect ratio, Rayleigh number and enclosure tile angle are provided. Heat flux and Nusselt number profiles are also computed. Validation with earlier simulations is also included [40]. Intricate vortex and thermal field structures are identified. The significant benefit of titling enclosures and scaling gravity (and therefore buoyancy) effects is shown. The computations and interpretation furnish useful insight into more realistic performance of direct absorber nanofluid solar collector designs and provide some guidance on achieving optimal specifications for aspect ratio, nano-particle volume fraction and orientation. Furthermore, the results are a useful compliment to laboratory investigations and indeed provide a good benchmark for further simulations with different nanoparticles.

\section{COMPUTATIONAL MATHEMATICAL MODEL}

The three-dimensional models of heat and fluid flow in the solar nanofluid absorber geometry (prismatic enclosure) are designed in ANSYS FLUENT computational fluid dynamics software [41]. The geometric configuration is illustrated in Fig. 1. Laminar, steady-state, incompressible flow is considered. The nanofluid is the absorber fluid and the Tiwari-Das nano-particle volume fraction model is deployed [42], which is described in due course. 
A dilute nanofluid suspension is assumed and the nano-particles are assumed to be in thermal equilibrium with the base fluid. There is no heat transfer though the top wall (adiabatic end condition). No slip boundary conditions are assumed on all walls of the enclosure (cavity). The walls are solid (impermeable). The fundamental equations for steady viscous, incompressible laminar flow and thermal convection are the three-dimensional time-independent NavierStokes equations and energy equation, which in a Cartesian coordinate system, take the following form:

$\frac{\partial v_{i}}{\partial x_{i}}=0$

$\rho_{n f} v_{j} \frac{\partial v_{j}}{\partial x_{j}}=-\frac{\partial p}{\partial x_{i}}+(\rho \beta)_{n f} g\left(T-T_{w}\right) \cos \alpha+\frac{\partial}{\partial x_{j}}\left[\mu_{n f}\left(\frac{\partial v_{i}}{\partial x_{j}}+\frac{\partial v_{j}}{\partial x_{i}}\right)\right]$

$\left(\rho c_{p}\right)_{n f} v_{j} \frac{\partial T}{\partial x_{j}}=\frac{\partial}{\partial x_{j}}\left(k_{n f} \frac{\partial T}{\partial x_{j}}\right)$

Here $v_{j}$ is the velocity vector $(u, v, w), x_{j}$ denotes $(x, y, z)$ coordinates, $\rho_{n f}$ is density of the nanofluid $\left(\mathrm{kg} / \mathrm{m}^{3}\right), \mu_{n f}$ is dynamic viscosity of the nanofluid $(\mathrm{kgm} / \mathrm{s}), c_{p}=$ specific heat capacity of the nanofluid $(\mathrm{J} / \mathrm{kg} . \mathrm{K}), k_{n f}$ is thermal conductivity of nanofluid $(\mathrm{W} / \mathrm{mK}), T$ denotes temperature $(K), g$ denotes gravity, $\beta$ is coefficient of thermal expansion and $\alpha$ is the enclosure orientation angle (tilt) to the vertical. When heat is added to the nanofluid, the density varies with temperature and flow can be induced due to the force of gravity mobilizing natural convection currents. In eqn. (2), the term $(\rho \beta)_{n f} g\left(T-T_{w}\right) \cos \alpha$ denotes the buoyancy force. Natural convection (buoyancy-driven flows) frequently employ the Boussinesq model. In this approach, constant density is specified, so the mass is properly calculated. This approach is valid provided the temperature differences in the domain are not excessive. The main benefit of Boussinesq model is that the simulation has faster convergence in comparison to setting up the problem with fluid density as a function of temperature. This model treats density as a constant value in all the solved equations in ANSYS FLUENT [43]. This approximation is accurate if changes in actual density are small; specifically, the Boussinesq approximation is valid when $\beta\left(T-T_{w}\right) \leq 1$. In ANSYS, this approach is implemented as a "one-phase flow" modification since the nano-particles are very small. A nanofluid is defined in the ANSYS FLUENT workbench as a "new fluid" with a new density, viscosity, thermal conductivity and specific heat obtained as a function of a base fluid and nano-particle type and concentration (volume fraction), according to Brinkman as described in Bég [27]. The nano-particle volume fraction can be estimated from: 


$$
\phi=\frac{v_{n p}}{v f}
$$

. The nanofluid dynamic viscosity can be estimated from:

$$
\mu_{n f}=\frac{\mu f}{(1-\phi)^{2.5}}
$$

The effective nanofluid density and heat capacity also can be estimated from:

$$
\begin{gathered}
\rho_{n f}=(1-\phi) \rho f+\phi \rho s \\
C p_{n f}=\frac{(1-\phi)(\rho C p)_{f}+\phi(\rho C p)_{s}}{\rho_{n f}}
\end{gathered}
$$

The effective thermal conductivity of fluid can be determined by the Maxwell-Garnet relation which is adopted by Tiwari and Das [47]:

$$
\frac{k n f}{k f}=\frac{k s+2 k f-2 \phi(k f-k s)}{k s+2 k f-\phi(k f-k s)}
$$

Here $k_{n f}=$ nanofluid thermal conductivity, $k_{f}=$ fluid thermal conductivity and $k_{s}=$ nanoparticle thermal conductivity (all in $\mathrm{W} / \mathrm{mK}$ ).

The key local dimensionless parameters which may be computed in ANSYS FLUENT [29, 41, 43] are local Rayleigh number (ratio of thermal buoyancy and viscous hydrodynamic force) and the average Nusselt number on the hot wall $(\overline{N u})$. These may be defined as:

$$
\begin{aligned}
& \text { Rayleigh number: } R a_{y}=\frac{g \beta}{V \alpha m}\left(T_{S}-T_{\infty}\right) y^{3} \\
& \text { Average Nusselt number: } \overline{N u}=\frac{\bar{h} L}{k}=\frac{q_{w C F D}^{\prime \prime}(L)}{k\left(T_{S}-T_{\infty}\right)}
\end{aligned}
$$

Here, $y$ is coordinate, $h$ is convection coefficient, $L$ is height of the enclosure, $q_{w C F D}^{\prime \prime}$ is the heat flux rate computed in ANSYS FLUENT (CFD code). Local Rayleigh number represents the ratio of thermal buoyancy and viscous hydrodynamic force. Average Nusselt number provides a measure for heat transfer rate along the hot wall of the three-dimensional enclosure. In addition to the no-slip boundary conditions at the walls of the enclosure, the following thermal boundary conditions are imposed:

Left hot wall: Constant temperature, $T=325 \mathrm{~K}$

Right cold wall: Constant temperature, $T=315 \mathrm{~K}$

The remaining walls: Adiabatic 


\section{ANSYS FLUENT GRID SENSITIVITY ANALYSIS}

An extensive mesh testing procedure was conducted to guarantee a grid-independent solution. The grid independence test has been performed on a cubical enclosure (i.e. aspect ratio $=1$ ) with $R a=10^{5}, \phi$ (volume fraction $)=0.02$ i.e. $2 \%$ gold nano-particles by volume. The tests were conducted for maximum element size of 0.08, 0.06, 0.05 and $0.04 \mathrm{~m}$. The average heat flux $(Q)$ on the hot wall is selected as a sensitive parameter. The results of the mesh variation are shown in Fig. 2. It is evident that the simulations attain mesh-independent convergence with approximately 40,000 tetrahedral (pyramid) elements. Therefore, this mesh density is deployed in all subsequent simulations. The meshed prismatic enclosure model is shown in Fig. 3.

\section{VALIDATION WITH PUBLISHED STUDIES}

To validate the results obtained from the ANSYS Model for natural convection inside a 3-D enclosure filled with aluminium oxide-water nanofluid, with a Rayleigh number of $10^{5}$, a comparison is conducted with the earlier study [40] for an aspect ratio of 1 (square enclosure) as shown in Figs. 4 and 5. The CFD simulation, using ANSYS FLUENT achieves close correlation with the results in [40] as is evident from the good agreement in streamline (isovelocity) and temperature contour patterns. The progressive distortion in temperature contours with distance from the heated left wall is clearly captured as is the strong vortex structure of the streamlines. Other test cases were also conducted to further confirm confidence in the ANSYS FLUENT model. Once confidence was established in the simulations further new simulations can be performed to examine specific effects of aspect ratio, Rayleigh number (buoyancy), volume fraction and enclosure inclination angle.

Fig. 6 illustrates the comparison of the ANSYS FLUENT computation non-dimensional temperature distribution along the horizontal centreline in the $Y / L=0.5$ plane with the Lattice Boltzmann method solution of Wang et al. [40]. Very close agreement is achieved confirming the accuracy of the ANSYS FLUENT simulations. Furthermore, Fig. 6 also confirms that the grid resolution of the ANSYS FLUENT simulation (40,000 elements) is of the requisite accuracy to produce the correct results.

\section{RESULTS AND DISCUSSION}

The ANSYS FLUENT results are depicted in Figs. 7a-e, Figs. 8a-b, Figs. 9a-c, Figs. 10a-e, Figs. 11-14 and Tables 2-4. The data utilized in a typical computation, for example with a gold 
nano-particle volume fraction $\phi$ of $5 \%$, based on the Tiwari-Das nanoscale model calculations is given in Table 1.

Figs. 7 a-e illustrate 3-dimensional temperature contour plots for impact of inclination angle $(\alpha)$ with volume fraction of $5 \%$, aspect ratio of 2 and a higher Rayleigh number of $R a=10^{5}$. Although five orientation (tilt) cases are studied ( $\alpha=0,10,30,45$ and 60 degrees) there are two plots per case. Table 2 shows the heat fluxes for the 5 tilt angles. It is apparent that with greater inclination of the enclosure there is a gradual enhancement in heat transfer from the left hot face (heated wall) towards the opposite cold wall, although this is concentrated in the uppermost section of the enclosure. Only at higher tilt angles does the green warmer zone penetrate deeper into the enclosure space and also dominates the upper face, left face completely. Temperature contours are also significantly expanded on the hot face around the central zone with increasing orientation of the enclosure. The thermal buoyancy force, $F_{\text {buoyancy }}$ equals $g \beta\left(T-T_{w}\right) \cos \alpha$, in the momentum equation (2) is clearly reduced with increasing angle of inclination. It is maximized for the vertical enclosure case and progressively reduced with increasing tilt angle. It is minimized for the horizontal enclosure case ( $\alpha \rightarrow 90$ degrees, cos $\alpha \rightarrow 0$ ). Scaling thermal buoyancy contribution via tilting the enclosure is therefore a simple but powerful mechanism for regulating temperature distribution in the solar collector. Table 2 shows the heat flux to the left wall (Nusselt number function) is decreased as inclination angle is increased since greater transfer of thermal energy deeper into the enclosure away from the hot wall is generated.

Figs. 8 a, b illustrate the 3-dimensional temperature contours in the solar enclosure for an increase in nano-particle volume fraction, $\phi=5,8 \%$. A substantial heating of the enclosure accompanies an increase in nano-particle volume fraction. The warm localized yellow-green contours originating at the left hot wall, are noticeably expanded and push the cooler central light blue contours further into the enclosure towards the opposite wall and sections of the dark blue colder zone vanish. The upper section of the opposite wall is heated with lighter blue (warmer) contours replacing the original darker blue ones. Nano-particle presence therefore extends the penetration distance of heat into the enclosure and increase thermal boundary layer thickness both at the upper face and the left hot face. Table 3 shows that heat flux is dramatically increased with greater nano-particle volume fraction. The presence of nanoparticles mobilizes micro-convection and encourages thermal diffusion away from the wall. This achieves the thermal enhancement. Similar findings have been reported by numerous 
authors including Tafarroj et al. [28], Fattahi et al. [30] Balakin et al. [31] and Nasrin et al. [35] for both carbon-based and metallic nanoparticles although they did not examine the case of gold.

Figs. 9a-c illustrate 3-dimensional temperature contour plots for impact of enclosure aspect ratio $(A R)$ with nano-particle volume fraction $(\phi)$ of $5 \%$, inclination angle of 30 degrees and Rayleigh number $R a=10^{6}$. AR defines the ratio of the height of the enclosure to either base dimension, where the base is always considered to be a square. Since three aspect ratio cases are examined, $(A R=1$ i.e. cubic enclosure, 2,4$)$ there are two plots per case i.e. a total of six visualizations are given. It is evident that there is a marked expansion of the warmer yellow/green upper left zone deeper into the body of the enclosure with a gradual replacement of darker colder blue contours with lighter blue warmer ones further and further towards the base and the right wall. For the highest aspect ratio yellow/green contours reach the right cold wall although they are confined to the upper area only. Table 4 shows the heat fluxes for all three aspect ratio cases studied. Aspect ratio is the only geometric parameter investigated and is important for providing some insight into the relative dimensions of the solar collector on heat transfer characteristics. The AR values selected are representative of actual configurations utilized in solar farms [44]. A significant elevation in surface heat flux is achieved with greater aspect ratio as shown in Table 4. This has also been computed by Esfandiary et al. [36] and Motlagh et al. [37] who also observed the deeper penetration of heat in enclosures with higher aspect ratio.

Figs. 10a-e show the influence of the Rayleigh number for nano-particle volume fraction $(\phi)$ of $5 \%$, inclination angle of 30 degrees and $A R=2$. Five Rayleigh number cases are examined $\left(\mathrm{Ra}=10^{3}, 10^{4}, 10^{5}, 10^{6}\right.$ and $\left.10^{7}\right)$. Initially there is an intensification in temperature contours only at the left hot wall with cooler light blue zones throughout the body of the enclosure and a cold blue zone at the far wall. This is modified to a localization of heat in the upper left zone of the enclosure with an increase in Rayleigh number from $10^{3}$ to $10^{4}$. This trend continues to prevail with further increment in Rayleigh number up to $10^{6}$. However, at very high Rayleigh number of $10^{7}$ (the temperature distribution achieved is much more homogenous) and the vast majority of the enclosure space is occupied by light blue warmer contours which also dominate the far wall. Significantly more balanced thermal diffusion through the enclosure is therefore achieved with very strong thermal buoyancy effect and there is a contraction in the yellow/red hot zone on the hot wall for this scenario. Rayleigh number (buoyancy) is overall a very dominant influence on thermofluid characteristics in the solar collector. 
In figs 11-14 the impact of the different parameters (nano-particle volume fraction, tilt angle, aspect ratio and Rayleigh number) on average Nusselt number at the hot wall are presented.

The average Nusselt number $\left(N u_{n f}\right)$ at the region of heat source is calculated and presented in Fig. 11 for the unity aspect ratio case $(A R=1)$ with a tilt angle of 30 degrees and Rayleigh number of $10^{4} \mathrm{Nu}$ f clearly decreases with the increase of volume faction. This can be explained by the fact that thermal conductivity of nanofluid $\left(k_{\mathrm{nf}}\right)$ is elevated with increasing volume faction, and consequently conductive heat transfer is increased whereas thermal convection heat transfer is reduced. This amplifies the temperature in the nanofluid and results in a transfer of heat from the wall manifesting in a decrease in Nusselt numbers. However, at around $0.08(8 \%)$ volume faction there is an upturn in Nusselt number which indicates that the heat transfer enhancement from conduction (associated with the nano-particles) decreases and this is also associated with the counter-productive increase in nanofluid effective viscosity. Therefore, the optimum nano-particle volume faction $\left(\phi_{\max }\right)$ is 0.07 (i.e. $7 \%$ ) and this is the maximum level of nanoparticle doping which benefits the solar collector performance. It is ideal to keep the Rayleigh number low so that the convective heat transfer from buoyancy force does not overcome the effect of conductive heat transfer from the gold nanoparticles. The optimal nano-particle volume fraction concurs with many other studies which have also reported an approximate upper limit of $8 \%$ volume fraction for thermal enhancement by nanoparticles $[33,40]$.

Fig 12 clearly shows that there is a linear decay in the Nusselt number with increasing inclination angle. This is associated with the depletion in thermal buoyancy force with increasing inclination angle. As noted earlier the maximum buoyancy force is achieved with the vertical orientation $(\alpha=0)$ of the prismatic enclosure $\left(g \beta\left(T-T_{w}\right) \cos \alpha \rightarrow g \beta\left(T-T_{w}\right)\right.$ since $\cos \alpha \rightarrow 1$ ). However, with increasing tilt angle, $\cos \alpha$ is progressively reduced reaching a minimum value of 0 when $\alpha \rightarrow 90$ degrees i.e. the horizontal enclosure case for which natural convection effects are minimized. Therefore, with greater inclination angle of the enclosure, heat transfer to the wall is reduced (Nusselt number is decreased) whereas thermal enhancement in the nanofluid itself i.e. temperatures within the circulating nanofluid are increased. Again, the ANSYS FLUENT simulations concur well with other studies on inclined nanofluid solar collectors including Esfandiary et al. [36], Motlagh et al. [37] and Ghachem et al. [38]. 
Fig. 13 shows that for a given nanoparticle volume faction of 0.05 and Rayleigh number of $10^{6}$ (laminar regime), with 30 degrees tilt angle, the average Nusselt number decreases with increasing aspect ratio. Although increasing aspect ratio has been shown to elevate temperatures in the gold-water nanofluid, this indicates that greater heat transfer from the boundary (wall) to the body of nanofluid is achieved with greater aspect ratio. This reduces the heat transfer to the boundary and therefore decreases average Nusselt numbers. Higher Nusselt number is therefore achieved with lower aspect ratio geometries whereas greater temperature enhancement is produced with higher aspect ratios. These trends are consistent with other investigations including Trodi and El Hocine Benhamza [45] and Bouhalleb and Abbassi [46]. The overall implication is that the influence of aspect ratio is stronger when the enclosure is taller and the Rayleigh number is high (but not too high).

Fig. 14 presents the variation of Nusselt number with Rayleigh number at fixed volume faction of 0.05 and inclination angle of 30 degrees and unity aspect ratio for the enclosure. There is a significant escalation in average Nusselt number with increasing Rayleigh number which due to the accentuation in thermal buoyancy force effect. Nusselt number increases significantly up to Rayleigh numbers of $10^{7}$ which constitutes the cut-off point for laminar convection flows. Beyond this limit the buoyancy forces overcome the viscous forces significantly and the heat transfer is dominated by convection at high Rayleigh number with the onset of turbulence, as noted by Braga and de Lemos [47]. Although further ANSYS FLUENT computations have also been made for shallow enclosures (aspect ratio <1), it was found that the effect of Rayleigh number on heat transfer is less significant for such scenarios and therefore these have been omitted for brevity.

\section{CONCLUSIONS}

A computational study of natural convection in an inclined 3-dimensional prismatic direct absorber solar collector (DASC) containing gold-water nanofluid has been presented. Steadystate, incompressible laminar Newtonian viscous flow is assumed. The enclosure has two adiabatic walls, one hot (solar receiving) and one colder wall. ANSYS FLUENT software (version 19.1) is employed. The Tiwari-Das volume fraction nanofluid model is utilized to simulate nanoscale effects and allows a systematic exploration of volume fraction effects. The effects of thermal buoyancy (Rayleigh number), geometrical aspect ratio and enclosure tilt angle on isotherm and temperature contour distributions are presented with extensive visualization in both two and three dimensions. Grid-independence tests are included. 
Validation with published studies from the literature is also conducted. The computations have shown that:

(i) Higher aspect ratio leads to improved heat transfer in the regime with deeper penetration of warmer zones in the enclosure.

(ii) Increasing Rayleigh number (thermal buoyancy force relative to viscous hydrodynamic force), there is an intensification in heat transfer from the left wall through the enclosure space and much more homogenous temperature distributions are eventually obtained.

(iii) With increasing nano-particle volume fraction, heat penetrates more effectively into the enclosure from the hot wall and temperature magnitudes are enhanced.

(iv) With greater inclination of the enclosure there is a progressive elevation in heat transfer from the left hot face (heated wall) towards the opposite cold wall, and temperatures are elevated mainly in the upper left zone with a more extensive warming in the central zone.

(v) Heat flux is dramatically increased with greater nano-particle volume fraction, and aspect ratio whereas it is suppressed with greater inclination of the enclosure.

(vi) Higher Nusselt number is therefore achieved with lower aspect ratio geometries whereas greater temperature enhancement is produced with higher aspect ratios.

(vii) There is a substantial boost in average Nusselt number with increasing Rayleigh number associated with the elevation in thermal buoyancy force effect.

(viii) With larger inclination angle of the prismatic enclosure, heat transfer to the wall is decreased (Nusselt number is depleted) whereas greater thermal enhancement in the nanofluid itself is achieved.

(ix) Nusselt number is significantly suppressed with an increase in gold nano-particle volume faction whereas temperatures are enhanced, both up to the cut-off volume fraction of $7 \%$.

(x) CFD finite volume methods (ANSYS FLUENT) provide an excellent tool for simulating solar nanofluid collector thermal fluid dynamic phenomena and offer a powerful compliment to experimental methods.

The present simulations have neglected thermal radiative heat transfer effects. These may be addressed with a number of radiation flux models in ANSYS FLUENT e.g. surface-to-surface (STS) model and the discrete ordinates model (DOM). Furthermore, the geometry considered 
has been planar. Many solar collector designs are now exploring curved geometries e.g. parabolic etc [48] and these are currently also under investigation by the authors.

\section{REFERENCES}

[1] W.J. Hiller et al., Visualization of 3-d natural convection, Flow Visualization VI, pp 474478, Springer, New York (1992).

[2] J. H. Ferziger, Computational Methods for Fluid Dynamics, Springer, New York (2001).

[3] G. D. Mallinson and G. De Vahl Davis, Three-dimensional natural convection in a box: a numerical study, J. Fluid Mechanics, 83, 1-31 (1977).

[4] T. Fusegi et al., A numerical study of 3D natural convection in a cube: effects of the horizontal thermal boundary conditions, Fluid Dynamics Research, 8, 10-20 (1991).

[5] Y. N. Sharma et al., Three-dimensional CFD simulation of thermosyphon flow in an unglazed solar flat plate collector, ASME 2013 International Mechanical Engineering Congress and Exposition, San Diego, California, USA, November 15-21 (2013).

[6] Z. Li et al., Lattice Boltzmann method simulation of 3-D natural convection with double MRT model, International Journal of Heat and Mass Transfer, 94, 222-238 (2016).

[7] C. Campos et al., About the relevance of particle shape and graphene oxide on the behavior of direct absorption solar collectors using metal based nanofluids under different radiation intensities, Energy Conversion and Management, 181, 247-257 (2019).

[8] A.R. Mallah et al., Blended morphologies of plasmonic nanofluids for direct absorption applications, Applied Energy, 229, 505-521 (2018).

[9] K. Farhana et al., Improvement in the performance of solar collectors with nanofluids- A state-of-the-art review, Nano-Structures \& Nano-Objects, 18 (2019). Article 100276

[10] X. Jin et al. Solar photothermal conversion characteristics of hybrid nanofluids: an experimental and numerical study, Renewable Energy, 141, 937-949 (2019).

[11] A. Gimeno-Furio et al., Characterization study of a thermal oil-based carbon black solar nanofluid, Renewable Energy, 140, 493-500 (2019).

[12] T.R. Shah et al., Applications of hybrid nanofluids in solar energy, practical limitations and challenges: A critical review, Solar Energy, 183, 173-203 (2019).

[13] M. S. Dehaj et al., Experimental investigation of heat pipe solar collector using MgO nanofluids, Solar Energy Materials and Solar Cells, 191, 91-99 (2019).

[14] E. Bellos et al., The use of nanofluids in solar concentrating technologies: A comprehensive review, J. Cleaner Production, 196, 84-99 (2018).

[15] K. Khanafer and K. Vafai, A review on the applications of nanofluids in solar energy field, Renewable Energy, 123, 398-406 (2018).

[16] M. E. Zayed et al., Factors affecting the thermal performance of the flat plate solar collector using nanofluids: A review, Solar Energy, 182, 382-396 (2019).

[17] R. Mehmood, Rabil Tabassum, S. Kuharat, O. Anwar Bég and M. Babaie, Thermal slip in oblique radiative nano-polymer gel transport with temperature-dependent viscosity: solar collector nanomaterial coating manufacturing simulation, Arabian J. Science and Engineering, 44 (2)1525-1541 (2019).

[18] S. Dugaria et al., Modelling of a direct absorption solar receiver using carbon based nanofluids under concentrated solar radiation, Renewable Energy, 128, 495-508 (2018).

[19] Y. Zhang et al., Enhancement of energy utilization using nanofluid in solar powered membrane distillation, Chemosphere, 212, 554-562 (2018).

[20] A. Zeiny et al., Solar evaporation via nanofluids: A comparative study, Renewable Energy, 122, 443-454 (2018). 
[21] O. Bait et al., Enhanced heat and mass transfer in solar stills using nanofluids: A review, Solar Energy, 170, 694-722 (2018).

[22] M. Mehrali et al., Full-spectrum volumetric solar thermal conversion via graphene/silver hybrid plasmonic nanofluids, Applied Energy, 224, 103-115 (2018).

[23] O. Anwar Bég, S. Kuharat, M. Ferdows, M. Das, A. Kadir, M. Shamshuddin, Magnetic nano-polymer flow with magnetic induction and nanoparticle solid volume fraction effects: solar magnetic nano-polymer fabrication simulation, Proc. IMechE-Part $N: \quad J$ Nanoengineering, Nanomaterials and Nano-systems (2019). DOI: 10.1177/ 2397791419838714 (19 pages)

[24] N. Shukla, Puneet Rana, O. Anwar Bég, A. Kadir and Bani Singh, Unsteady electromagnetic radiative nanofluid stagnation-point flow from a stretching sheet with chemically reactive nanoparticles, Stefan blowing effect and entropy generation, Proc. IMechE: Part N-Journal of Nanomaterials, Nanoengineering and Nanosystems, 232, 69-82 (2018).

[25] G.Martinopoulos et al., CFD modeling of a polymer solar collector, Renewable Energy, 35, 1499-1508 (2010).

[26] J. Prakash, E.P. Siva, D Tripathi, S. Kuharat and O. Anwar Bég, Peristaltic pumping of magnetic nanofluids with thermal radiation and temperature-dependent viscosity effects: modelling a solar magneto-biomimetic nanopump, Renewable Energy, 133, 1306-1326 (2019). [27] O. Anwar Bég, Nonlinear multi-physical laminar nanofluid bioconvection flows: Models and computation, A. Sohail, Z. Li (Eds.): Computational Approaches in Biomedical NanoEngineering, Wiley, Chapter 5, pp. 113-145 (2018). ISBN: 3527344721,9783527344727

[28] M.M. Tafarroj et al., CFD modeling and predicting the performance of direct absorption of nanofluids in trough collector, Applied Thermal Engineering, 148, 256-269 (2019).

[29] S. Kuharat, O. Anwar Bég, Ali Kadir and M. Babaie, Computational fluid dynamic simulation of a solar enclosure with radiative flux and different metallic nano-particles, International Conference on Innovative Applied Energy (IAPE'19), St Cross College, University of Oxford, United Kingdom, 14-15 March (2019).

[30] E. Fattahi et al., Lattice Boltzmann simulation of natural convection heat transfer in nanofluids, International Journal of Thermal Sciences, 52, 137-144 (2012).

[31] B. Balakin et al., Direct absorption solar collector with magnetic nanofluid: CFD model and parametric analysis, Renewable Energy, 136, 23-32 (2019).

[32] M. Selmi et al., Validation of CFD simulation for flat plate solar energy collector, Renewable Energy, 33, 383-387 (2008).

[33] B.A.J. Rose et al., Investigations into nanofluids as direct solar radiation collectors, Solar Energy, 147, 426-431 (2017).

[34] H. Nasiri et al., A smoothed particle hydrodynamics approach for numerical simulation of nano-fluid flows: Application to forced convection heat transfer over a horizontal cylinder, J. Thermal Analysis and Calorimetry (2018). DOI: 10.1007/s10973-018-7022-4

[35] R. Nasrin et al., Effect of Prandtl number on free convection in a solar collector filled with nanofluid, Proc. Eng., 56, 54-62 (2013).

[36] M. Esfandiary et al., Natural convection of Al2O3-water nanofluid in an inclined enclosure with the effects of slip velocity mechanisms: Brownian motion and thermophoresis phenomenon, International Journal of Thermal Sciences, 105, 137-158 (2016).

[37] S. Y. Motlagh et al., Natural convection of Al2O3-water nanofluid in an inclined cavity using Buongiorno's two-phase model,_Int. J. Thermal Sciences, 111, 310-320 (2017).

[38] K. Ghachem et al., Numerical study of combined natural convection and radiation in threedimensional solar thermal collector: focus on the inclination effect on heat transfer, American Journal of Modern Energy, 1(2): 44-51 (2015). 
[39] Baek, S. et.al. Au@ Ag core-shell nanocubes for efficient plasmonic light scattering effect in low bandgap organic solar cells. ACS Nano. 8 (4), 3302-3312 (2014).

[40] L. Wang, B. Shi and Z. Chai, Effects of temperature-dependent properties on natural convection of nanofluids in a partially heated cubic enclosure, Applied Thermal Engineering, 128, 204-213 (2018).

[41] Sireetorn Kuharat and O. Anwar Bég, Simulation of a nanofluid-based annular solar collector, ICHTFM 2018: 20th International Conference on Heat Transfer and Fluid Mechanics, Istanbul, Turkey, August 16 - 17 (2018).

[42] R.J. Tiwari, M.K. Das, Heat transfer augmentation in a two-sided lid-driven differentially heated square cavity utilizing nanofluids, Int. J. Heat. Mass Transf., 50, 2002-2018 (2007).

[43] S. Kuharat, O. Anwar Bég, A. Kadir and M. Shamshuddin, Computational study of heat transfer in solar collectors with different radiative flux models, Heat Transfer Asian Research, 48, 1002-1031 (2019).

[44] S. A. Kalogirou, Solar Energy Engineering: Processes and Systems, Academic Press, USA (2014).

[45] A. Trodi and M. El Hocine Benhamza, Particle shape and aspect ratio effect of $\mathrm{al}_{2} \mathrm{O}_{3}-$ water nanofluid on natural convective heat transfer enhancement in differentially heated square enclosures, Chemical Engineering Communications, 204:2, 158-167 (2017).

[46] M. Bouhalleb and H. Abbassi, Natural convection of nanofluids in enclosures with low aspect ratios, International Journal of Hydrogen Energy, 39,_15275-15286 (2014).

[47] E. J. Braga and M. J.S.de Lemos, Laminar and turbulent free convection in a composite enclosure, Int. J. Heat Mass Transfer, 52, 588-596 (2009).

[48] M. H. Abadshapoori and M.H. Saidi Lattice Boltzmann simulation of $\mathrm{TiO}_{2}$-water nanofluid in a curved boundary domain at high Rayleigh numbers, Computers \& Fluids, 168, 159-169 (2018).

\section{TABLES}

\begin{tabular}{|c|c|c|}
\hline Property & Value & Units \\
\hline Grashof number $(\mathrm{Ra} / \mathrm{Pr})$ & $2.45 \times 10^{4}$ & - \\
\hline Rayleigh number $(\mathrm{Ra})$ & $10^{5}$ & $\mathrm{~kg} / \mathrm{m}^{3}$ \\
\hline Gold density $\left(\rho_{\mathrm{p}}\right)$ & 1912.245 & $1 / \mathrm{K}$ \\
\hline Gold thermal expansion $(\beta)$ & $1.11 \times 10^{-4}$ & $\mathrm{~m}$ \\
\hline Height of enclosure $(\mathrm{L})$ & 0.5 & $\mathrm{~m}^{2} / \mathrm{s}$ \\
\hline Water kinematic viscosity $(v)$ & $6.42 \mathrm{E}-07$ & $\mathrm{~m}^{2} / \mathrm{s}$ \\
\hline Water thermal diffusivity $\left(\alpha_{\mathrm{m}}\right)$ & $1.57355 \mathrm{E}-07$ & $\mathrm{~m} / \mathrm{s}^{2}$ \\
\hline Gravity $(\mathrm{g})$ & 9.81 & $\mathrm{~K}$ \\
\hline Temperature difference $(\Delta \mathrm{T})$ & 10 & $\mathrm{~J} / \mathrm{kg} . \mathrm{K}$ \\
\hline Nanofluid Specific Heat $\left(\mathrm{C} \mathrm{p}_{\mathrm{nf}}\right)$ & 2133.684154 & $\mathrm{~W} / \mathrm{m} . \mathrm{K}$ \\
\hline Nanofluid thermal conductivity $\left(\mathrm{K}_{\mathrm{nf}}\right)$ & 0.642029776 & $\mathrm{~kg} / \mathrm{m} . \mathrm{s}$ \\
\hline Nanofluid dynamic viscosity $\left(\mu_{\mathrm{nf}}\right)$ & 0.001227536 & \\
\hline Prandtl number $(\operatorname{Pr})$ & 4.079521928 & \\
\hline
\end{tabular}

Table 1: Thermophysical and hydrodynamic properties of gold nano-particles and gold-water nanofluid

\begin{tabular}{|c|c|}
\hline Tilt angle $(\alpha)$ & Surface Heat Flux $Q\left(\mathrm{~W} / \mathrm{m}^{2}\right)$ \\
\hline 0 & 83.872254 \\
\hline 10 & 80.130418 \\
\hline 30 & 70.722287 \\
\hline
\end{tabular}




\begin{tabular}{|c|c|}
\hline 45 & 60.323023 \\
\hline 60 & 47.4667 \\
\hline
\end{tabular}

Table 2. Heat flux computed on hot wall for gold-water nanofluid, with $\phi=5 \%, A R=2$ and $R a=10^{5}$ for inclination $(\alpha)=60$ degrees.

\begin{tabular}{|c|c|}
\hline Volume Fraction $(\phi)$ & Surface Heat Flux $Q\left(\mathrm{~W} / \mathrm{m}^{2}\right)$ \\
\hline 0.02 & 69.212486 \\
\hline 0.05 & 70.722287 \\
\hline 0.08 & 72.398288 \\
\hline 0.11 & 73.886681 \\
\hline 0.14 & 75.408061 \\
\hline
\end{tabular}

Table 3. Heat flux computed on hot wall for gold-water nanofluid, with $\alpha=30$ degrees $A R=2$ and $R a$ $=10^{5}$ for different gold nano-particle volume fractions $(\phi)$.

\begin{tabular}{|c|c|}
\hline Aspect ratio $(A R)$ & Surface Heat Flux $Q\left(\mathrm{~W} / \mathrm{m}^{2}\right)$ \\
\hline 1 & 56.805868 \\
\hline 2 & 70.722287 \\
\hline 4 & 74.055584 \\
\hline
\end{tabular}

Table 4. Heat flux computed on hot wall for gold-water nanofluid, with $\alpha=30$ degrees, $R a=10^{6}$ and gold volume fraction $(\phi)=5 \%$ for various aspect ratios $(A R)$.

\section{FIGURES}

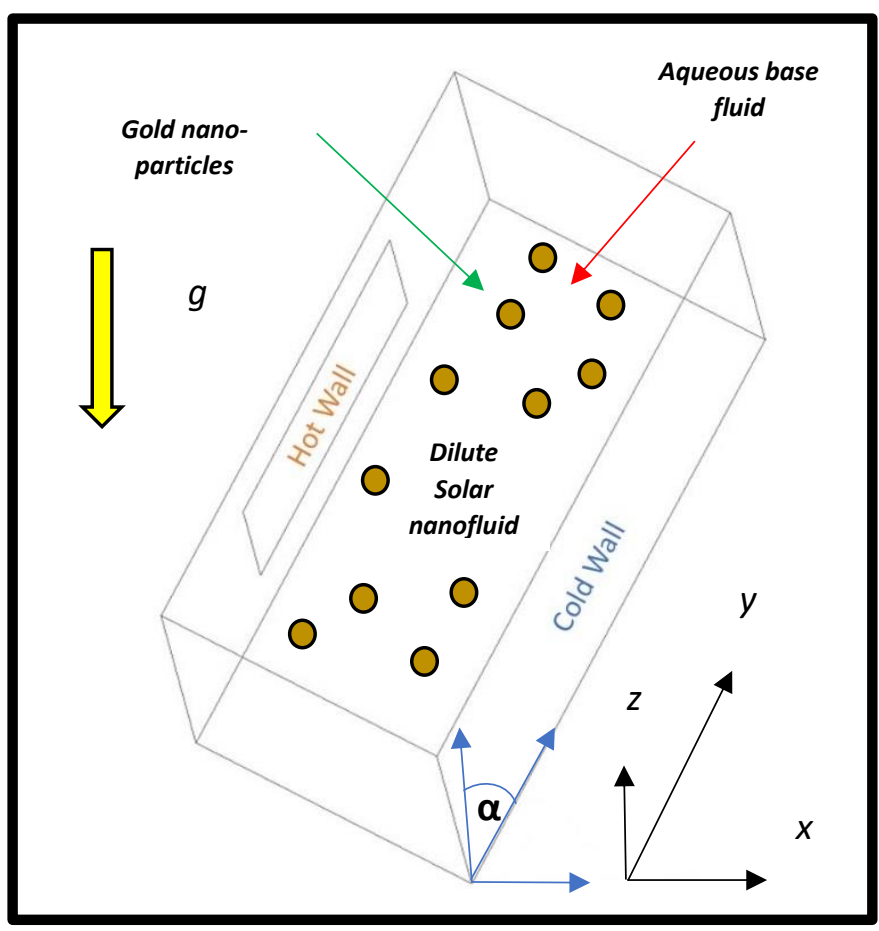

Fig 1: 3-dimensional solar nanofluid absorber prismatic geometry 


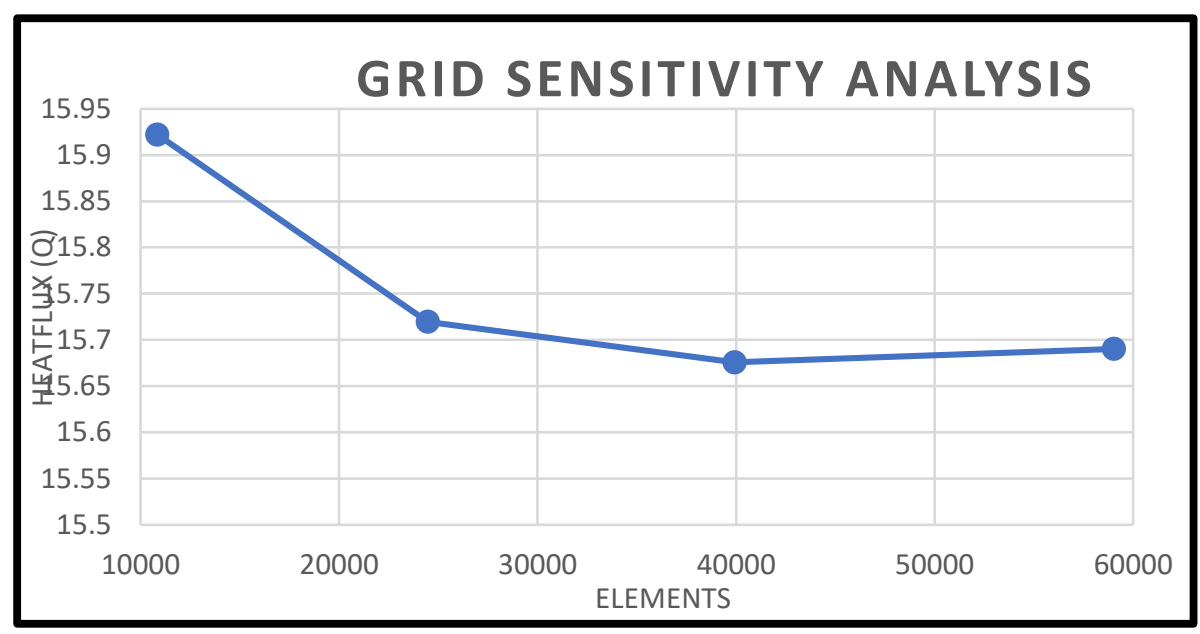

Fig. 2: Finite volume ANSYS FLUENT grid independence study

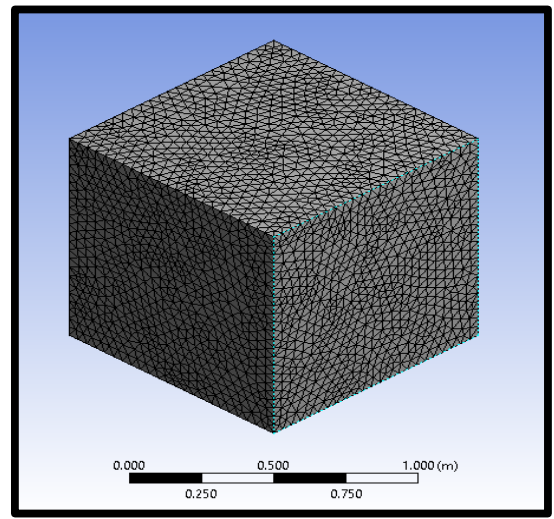

Fig. 3: ANSYS 3-D mesh for nanofluid prismatic collector

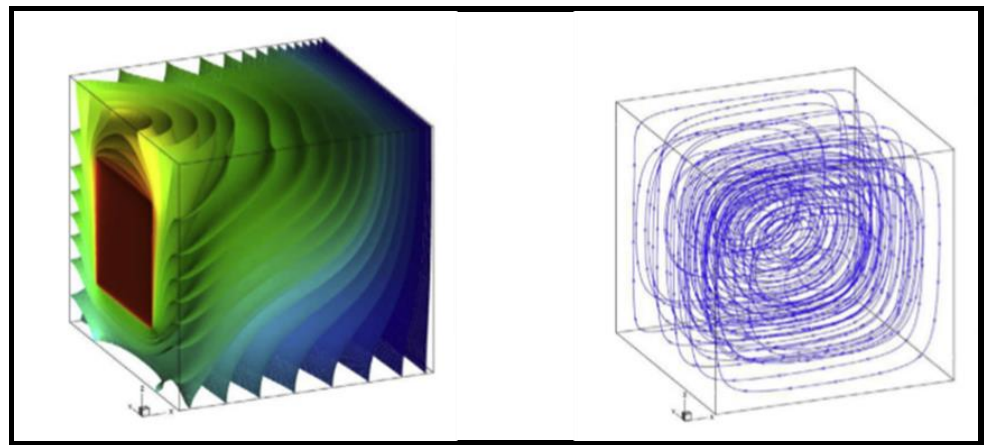

Fig 4: Benchmark case for validation with LBM results of Wang et al. [40]

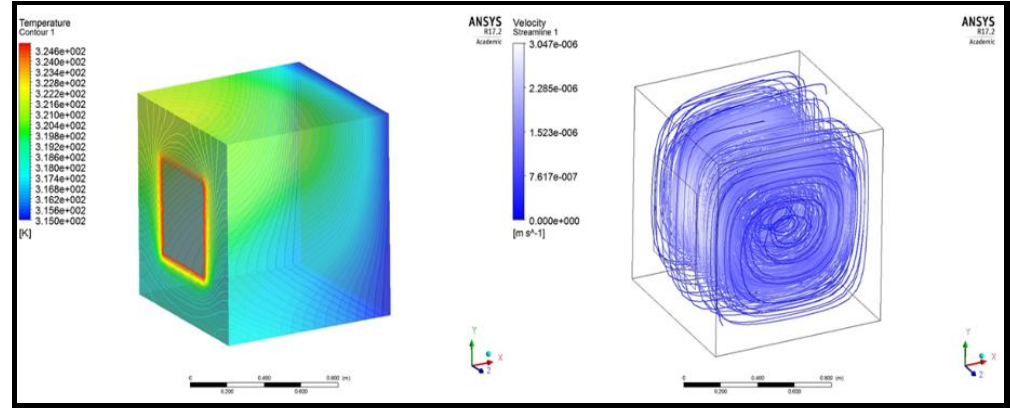

Fig 5. Present ANSYS FLUENT streamline and isotherm results 


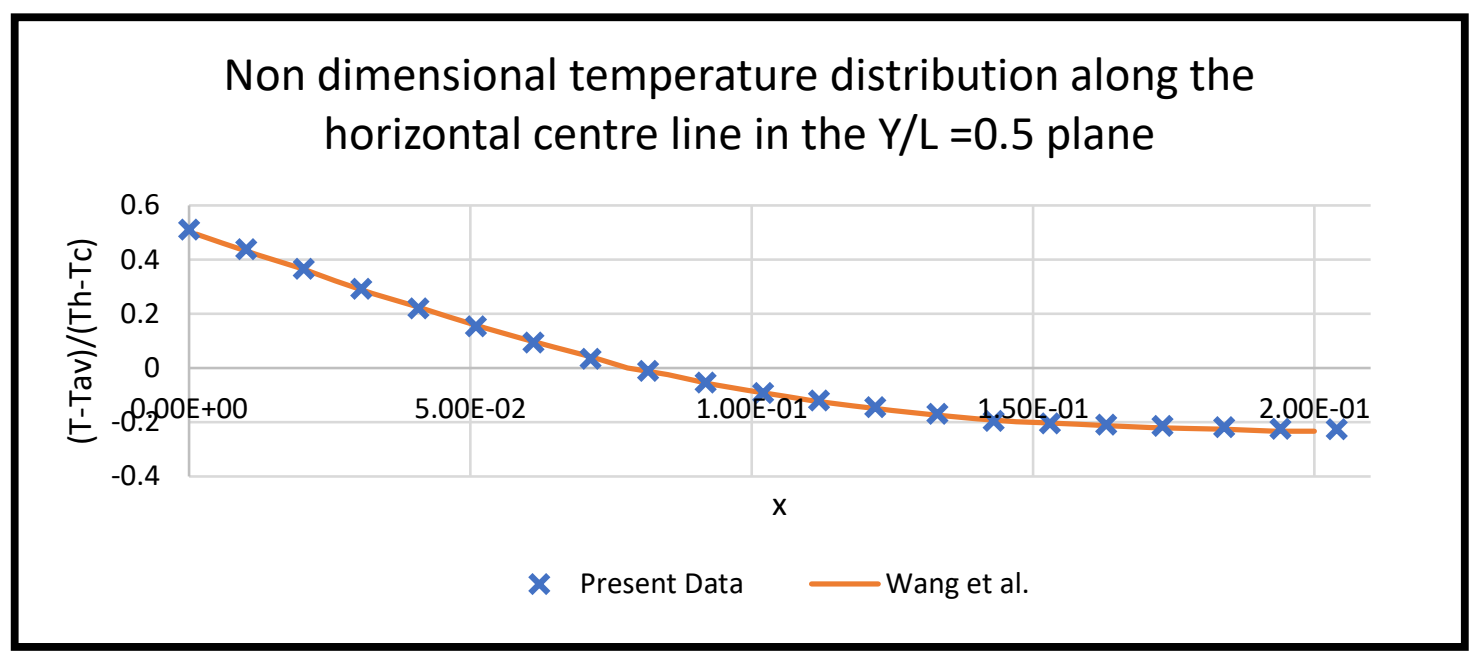

Fig 6: Comparison of ANSYS FLUENT solution ( $\times$ ) and LBM results (-) of Wang et al. [40]

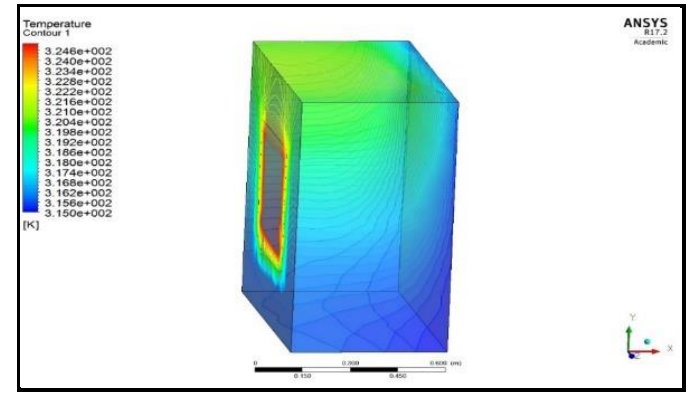

Fig 7a. 3-D full body temperature contours for gold-water nanofluid, with $\phi=5 \%, A R=2$ and $R a=10^{5}$ for inclination $(\alpha)=0$ degrees (vertical orientation).

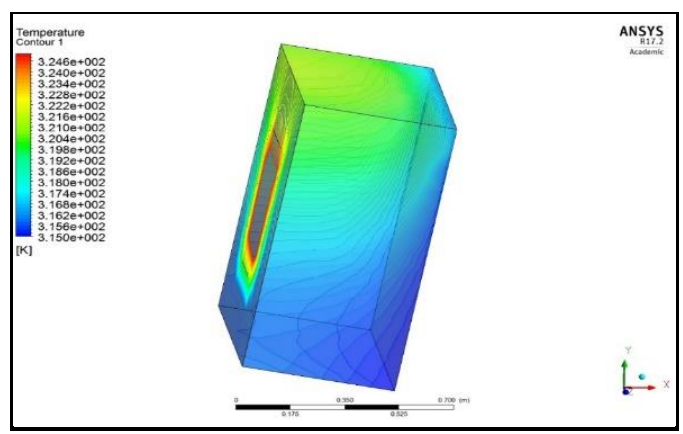

Fig 7b. 3-D full body temperature contours for gold-water nanofluid, with $\phi=5 \%, A R=2$ and $R a=10^{5}$ for inclination $(\alpha)=10$ degrees (weak tilt orientation).

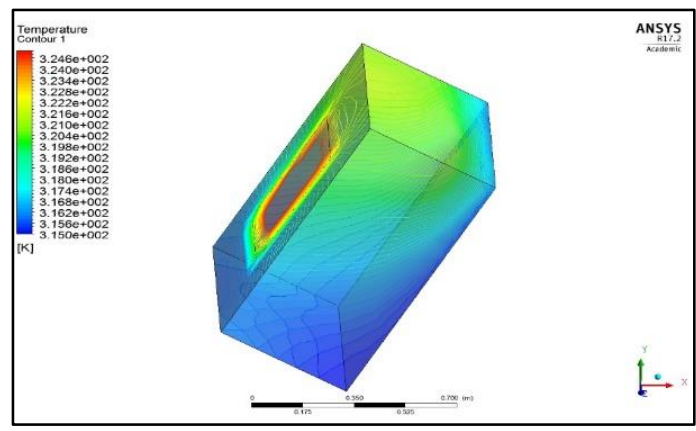

Fig 7c. 3-D full body temperature contours for gold-water nanofluid, with $\phi=5 \%, A R=2$ and $R a=10^{5}$ for inclination $(\alpha)=30$ degrees. 


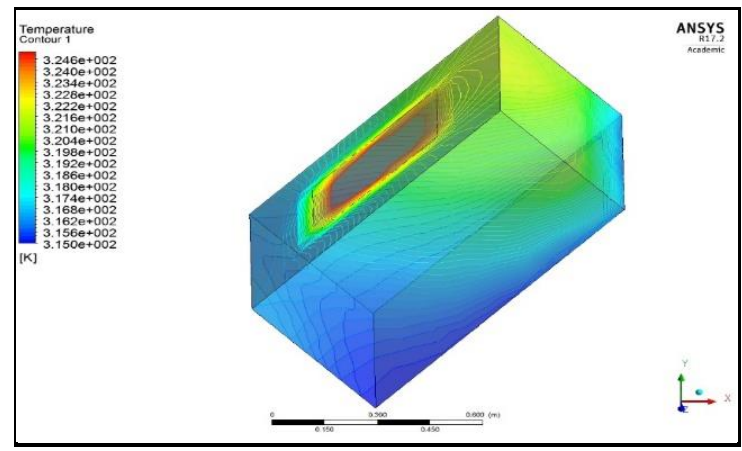

Fig 7d. 3-D full body temperature contours for gold-water nanofluid, with $\phi=5 \%, A R=2$ and $R a=10^{5}$ for inclination $(\alpha)=45$ degrees.

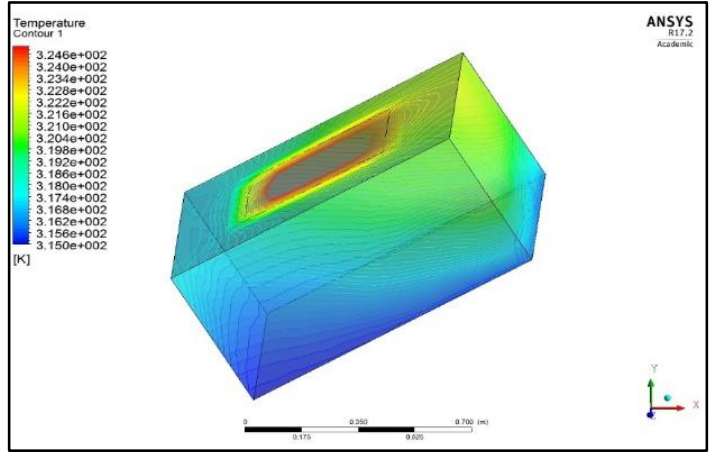

Fig 7e. 3-D full body temperature contours for gold-water nanofluid, with $\phi=5 \%, A R=2$ and $R a=10^{5}$ for inclination $(\alpha)=60$ degrees.

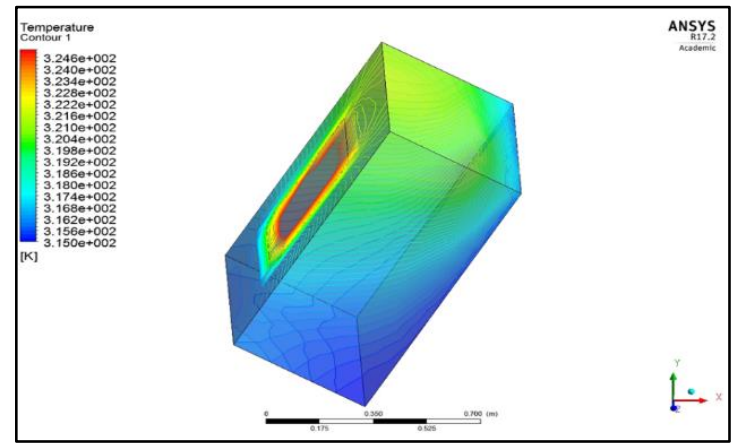

Fig 8a. 3-D full body temperature contours for gold-water nanofluid, with $\alpha=30$ degrees, $A R=2$ and $R a=10^{5}$ for gold volume fraction $(\phi)=5 \%$.

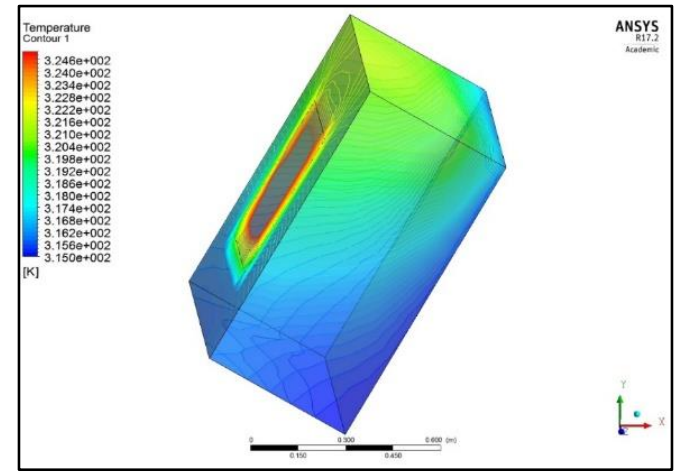

Fig 8b. 3-D full body temperature contours for gold-water nanofluid, with $\alpha=30$ degrees, $A R=2$ and $R a=10^{5}$ for gold volume fraction $(\phi)=8 \%$. 


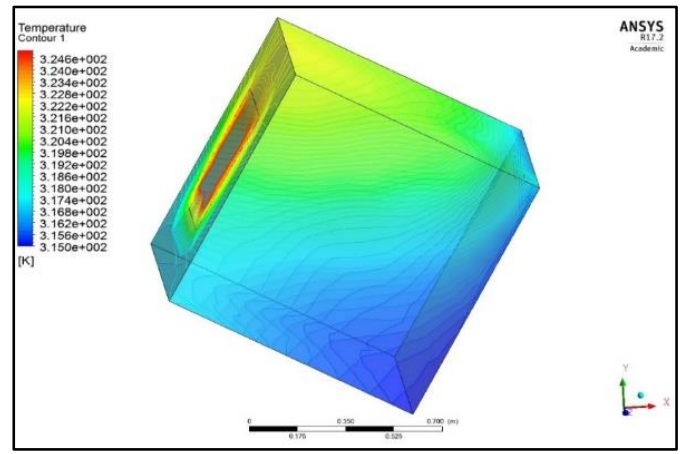

Fig 9a. 3-D full body temperature contours for gold-water nanofluid, with $\alpha=30$ degrees, $R a=10^{6}$ and gold volume fraction $(\phi)=5 \%$ for $A R=1$ (cubical enclosure).

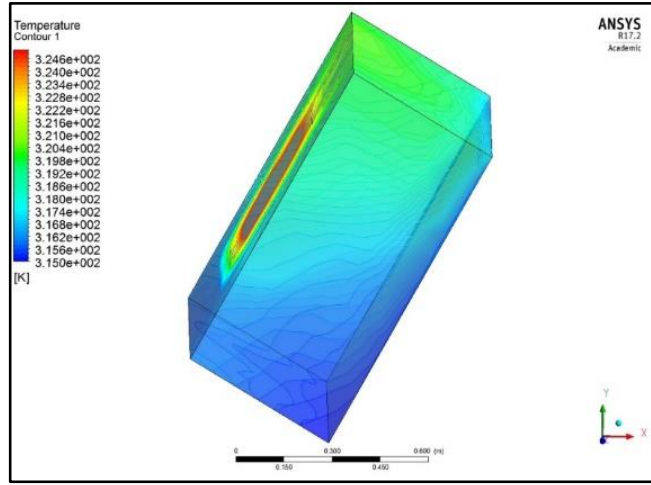

Fig 9b. 3-D full body temperature contours for gold-water nanofluid, with $\alpha=30$ degrees, $R a=10^{6}$ and gold volume fraction $(\phi)=5 \%$ for $A R=2$.

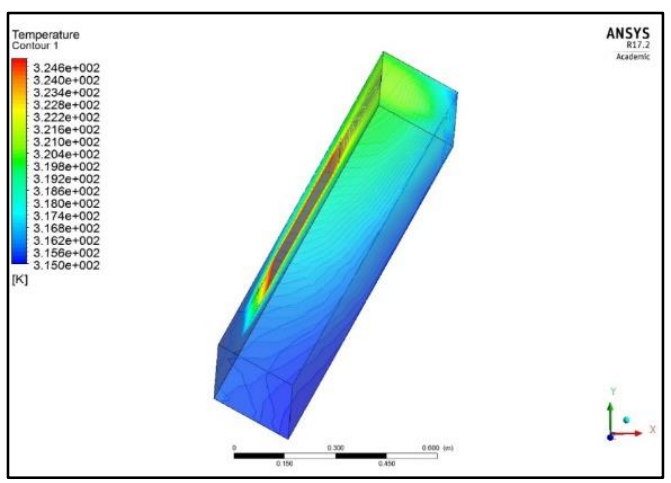

Fig 9c. 3-D full body temperature contours for gold-water nanofluid, with $\alpha=30$ degrees, $R a=10^{6}$ and gold volume fraction $(\phi)=5 \%$ for $A R=4$ (slender enclosure).

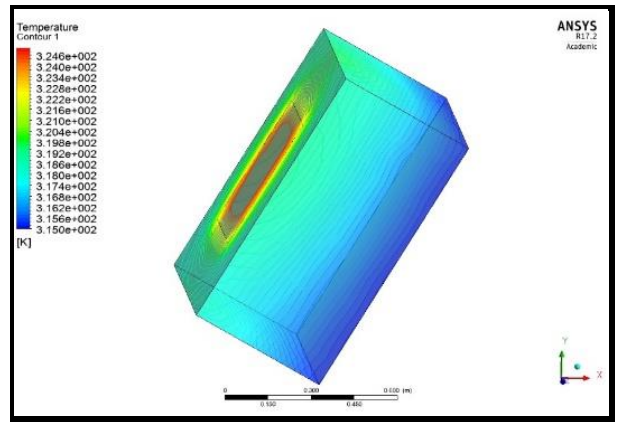

Fig 10a. 3-D full body temperature contours for gold-water nanofluid, with $\alpha=30$ degrees, $A R=2$ and gold volume fraction $(\phi)=5 \%$ for $R a=10^{3}$. 


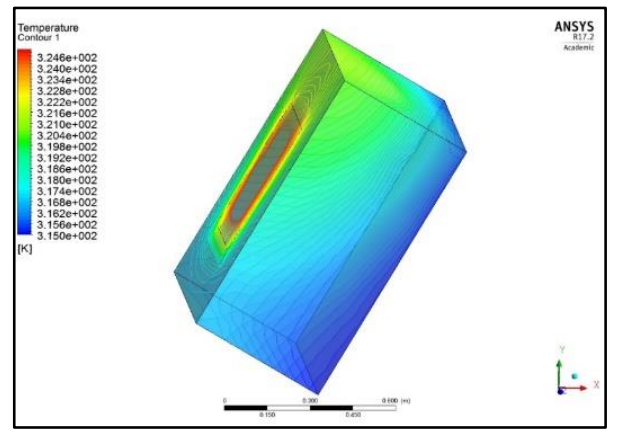

Fig 10b. 3-D full body temperature contours for gold-water nanofluid, with $\alpha=30$ degrees, $A R=2$ and gold volume fraction $(\phi)=5 \%$ for $R a=10^{4}$.

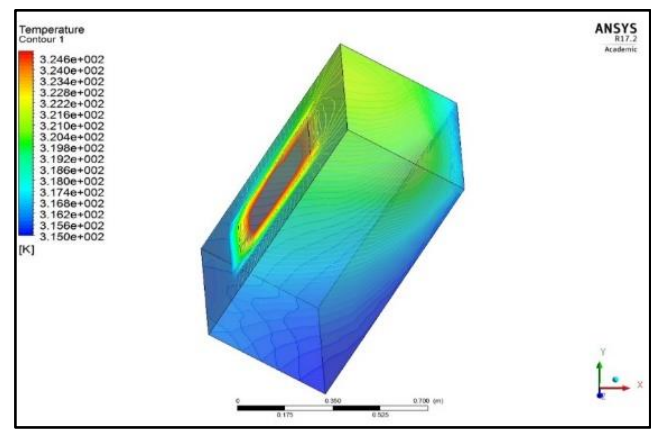

Fig 10c. 3-D full body temperature contours for gold-water nanofluid, with $\alpha=30$ degrees, $A R=2$ and gold volume fraction $(\phi)=5 \%$ for $R a=10^{5}$.

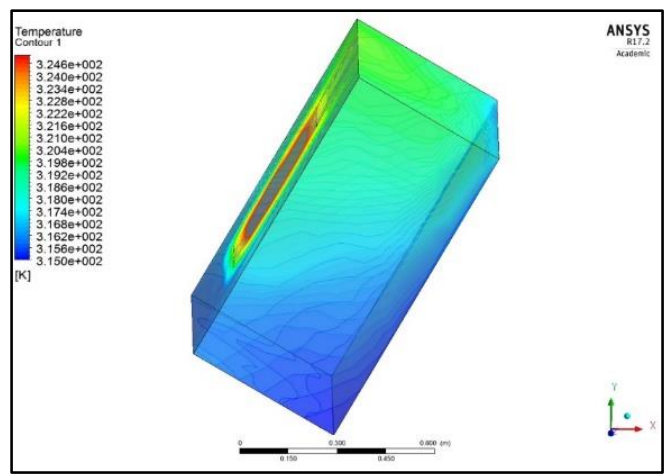

Fig 10d. 3-D full body temperature contours for gold-water nanofluid, with $\alpha=30$ degrees, $A R=2$ and gold volume fraction $(\phi)=5 \%$ for $R a=10^{6}$.

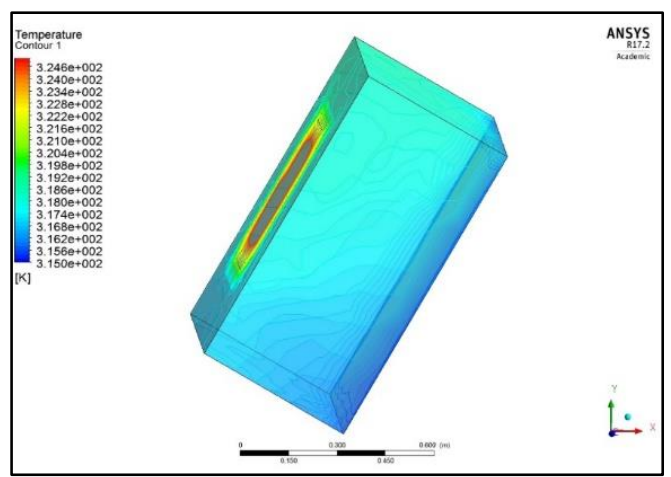

Fig 10e. 3-D full body temperature contours for gold-water nanofluid, with $\alpha=30$ degrees, $A R=2$ and gold volume fraction $(\phi)=5 \%$ for $R a=10^{7}$. 


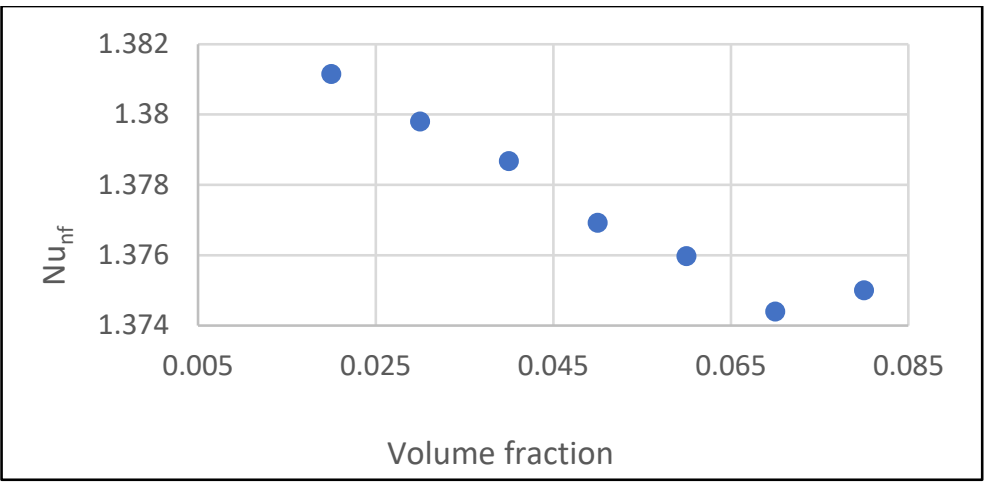

Fig. 11: Average Nusselt number versus volume fraction $(\phi)$

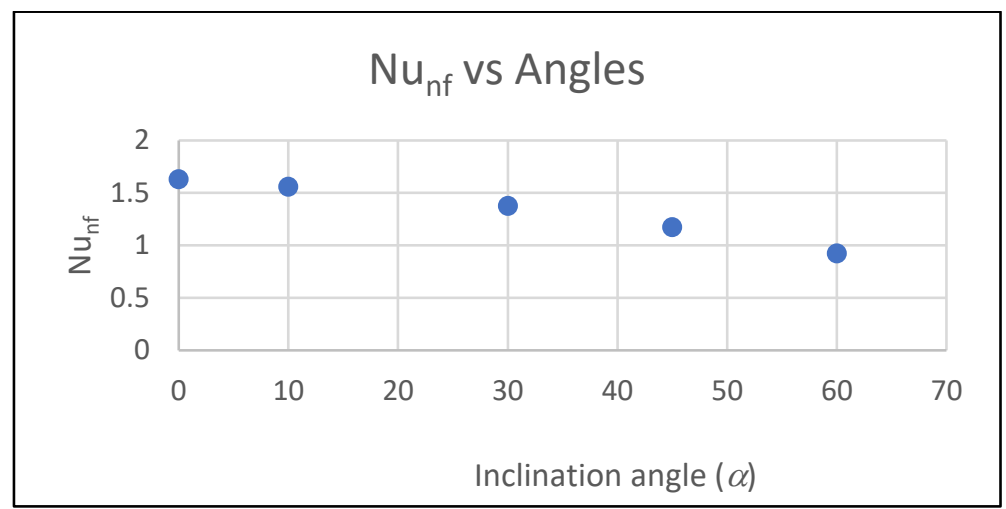

Fig. 12: Average Nusselt number versus enclosure inclination angle $(\alpha)$

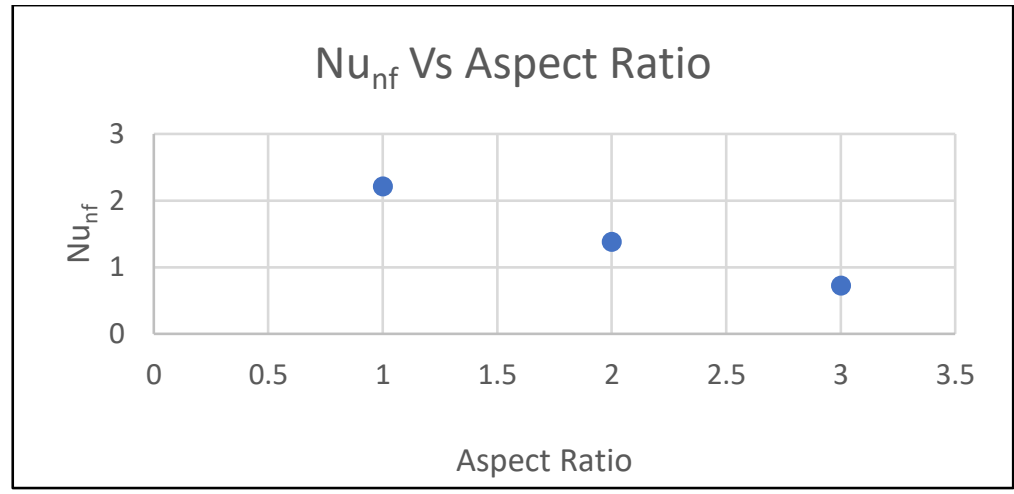

Fig. 13: Average Nusselt number versus enclosure aspect ratio

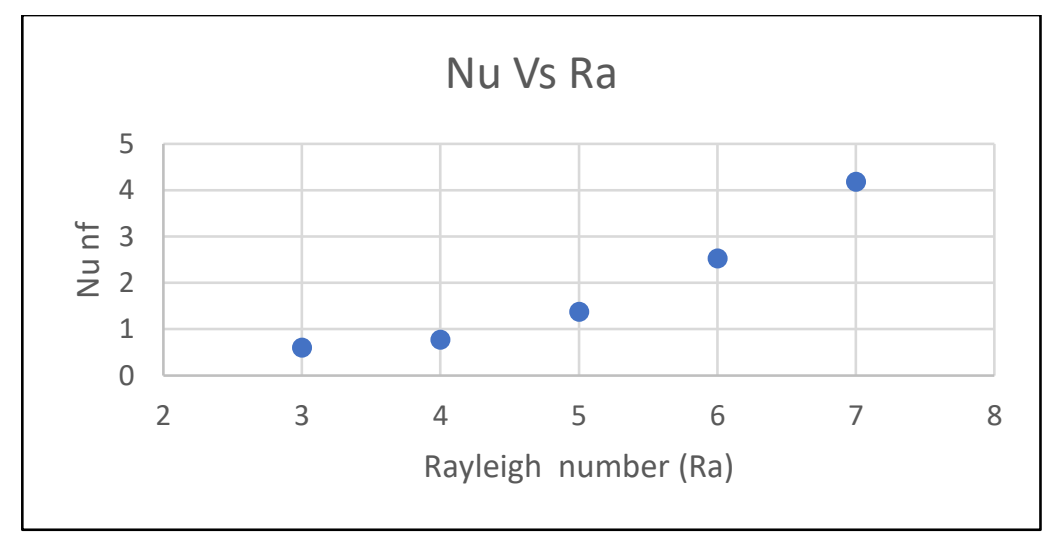

Fig. 14: Average Nusselt number versus Rayleigh number $(R a)$ 